\title{
Incidência de A.Ochraceus em Grãos de Café (Coffea arábica L.) Beneficiados, em Diferentes Regiões Produtoras de Minas Gerais.
}

Thaiana Marinha de Almeida Sousa $(I, I, I)$, Luis Roberto Batista $(I, I)$, Sarah Maria Chalfoun (III,I,III), Nathasha Azevedo Lira (I,I)

(I) UFLA - Universidade Federal de Lavras (UNIVERSIDADE FEDERAL DE LAVRAS Câmpus Universitário, Caixa Postal 3037, CEP 3720), (II) UFLA - Universidade Federal de Lavras (UNIVERSIDADE FEDERAL DE LAVRAS Câmpus Universitário, Caixa Postal 3037, CEP 3720), (III) EPAMIG - Empresa de Pesquisa Agropecuária de Minas Gerais (Rodovia Lavras/ ljaci km 02 Campus da UFLA Lavras - MG CEP: 37200-000)

\section{Resumo}

As condições climáticas, a localização geográfica da região produtora e os processos envolvidos na produção de café, podem influenciar nas características do grão, podendo torná-los susceptíveis à contaminação fúngica. Sabendo-se que o fungo A. ochraceus desenvolve-se em uma grande faixa de temperatura de 8 a $30^{\circ} \mathrm{C}$, e a temperatura ótima de crescimento está na faixa de 25 a $30^{\circ} \mathrm{C}$ e em aw mínima para o desenvolvimento de 0,76 , pode-se avaliar o desenvolvimento e a incidência do mesmo nas regiões avaliadas. O objetivo deste estudo foi avaliar grãos crus de café ( Coffea arábica L. ) advindos de diferentes regiões produtoras do estado de Minas Gerais quanto a incidência de Aspergillus ochraceus. Foram coletadas 30 amostras classificadas como bebida dura em cooperativas. Dez amostras pertencentes a região da Zona da Mata, 10 a região do Cerrado e 10 pertencentes à região do Sul de Minas. A metodologia de análise foi realizada a partir da desinfecção dos grãos crus com hipoclorito a $1 \%$ e água destilada. Com os grãos superficalmente desinfeccionados foi realizado o plaqueamento direto em meio dicloran rosa de bengala clorafenicol por 5 dias a $25^{\circ} \mathrm{C}$, posteriormente as colônias foram purificadas em meio ágar malte (MA) durante sete dias a $25^{\circ} \mathrm{C}$, em seguida foram inoculadas em meio CYA(Czapek) e MEA(Extrato de Malte

\footnotetext{
Referência:

Thaiana Marinha de Almeida Sousa, Luis Roberto Batista, Sarah Maria Chalfoun, Nathasha Azevedo Lira.Incidência de A.Ochraceus em Grãos de Café (Coffea Arábica L.) Beneficiados, em Diferentes Regiões Produtoras de Minas Gerais.. In: Anais do $12^{\circ}$ Congresso Latinoamericano de Microbiologia e Higiene de Alimentos - MICROAL 2014 [= Blucher Food Science Proceedings, num.1, vol.1]. São Paulo: Editora Blucher, 2014. 
Agar) durante 7 dias a $25^{\circ} \mathrm{C}$ e $37^{\circ} \mathrm{C}$ para a identificação microscópica das espécies de acordo com Klich (2002). Foram identificados 11 isolados Aspergillus ochraceus na região da Zona da Mata, 8 isolados na região do Cerrado e 1 isolado foi encontrado na região do Sul de Minas. As regiões diferiram estatisticamente entre si agrupando-se as médias por Scott Knott à $\mathrm{p}<0,05$, e pelo teste de $\mathrm{F}$ a $\mathrm{p}<0,05$ para testar os contrastes de interesse entre as regiões avaliadas, sendo a região da Zona da Mata mais expressiva, seguida da região do Cerrado e Sul de Minas respectivamente. Paterson e Lima (2010) afirmam que a contaminação por fungos ocratoxigênicos em grãos de café ocorre na presença de condições específicas, como clima, suscetibilidade da planta, fatores intrínsecos e extrínsecos, o cultivo do produto, o manuseio, os nutrientes do substrato e a genética dos microrganismos. A região Zona da Mata de Minas caracteriza-se por temperaturas relativamente altas e acúmulo de umidade nos locais de plantio e de secagem do café (CORTEZ, 1997; CARVALHO; CHAGAS; SOUZA, 1997). Estes fatores podem contribuir para o desenvolvimento de microrganismos, tais como os fungos das seções A. nigri e A.Circumdatti na região da Zona da Mata.

Palavras-Chave: Aspergillus, coffea arabica, ocratoxina A Agência de Fomento: 